\title{
Erratum to: Calcium buffering and clearance in spider mechanosensory neurons
}

\author{
Joscha Schmitz • Ulli Höger · Päivi H. Torkkeli • \\ Andrew S. French
}

Published online: 25 December 2013

(c) Springer-Verlag Berlin Heidelberg 2013

Erratum to: J Comp Physiol A (2012) 198:477-483

DOI 10.1007/s00359-012-0717-2

The author would like to correct the errors in the publication of the original article. The corrected details are given below for your reading.

Acknowledgement section should read as:

The study was supported by Canadian Institutes of Health Research and Natural Sciences and Engineering Research Council of Canada. Shannon Meisner provided excellent technical assistance. This project has been funded with support from the European Commission. This publication [communication] reflects the views only of the authors, and the Commission cannot be held responsible for any use which may be made of the information contained therein.

The online version of the original article can be found under doi:10.1007/s00359-012-0717-2.

J. Schmitz · U. Höger · P. H. Torkkeli · A. S. French ( $\bowtie)$ Department of Physiology and Biophysics, Dalhousie University, PO BOX 15000, Halifax, NS B3H 4R2, Canada e-mail: andrew.french@dal.ca 